\title{
Evaluation of condylar structures on panoramic radiographs in adolescent patients with coeliac disease
}

\author{
M.A. Yavan', E. Isman², S. Kocahan³ ${ }^{3}$ \\ ${ }^{1}$ Department of Orthodontics, Faculty of Dentistry, University of Adiyaman, Turkey \\ 2Private Orthodontist, Gaziantep, Turkey \\ ${ }^{3}$ Department of Physiology, Faculty of Medicine, University of Adiyaman, Turkey \\ "International Scientific Centre, Baku State University, Baku, Azerbaijan \\ [Received: 26 April 2018; Accepted: 21 May 2018]
}

Background: Coeliac disease (CD) is a common disorder that usually originates from calcium malabsorption. Thus, it is accepted that patients with CD have lower bone mineral density than that of healthy individuals. The aim of this study was to assess condylar height, width, area, and perimeter on digital panoramic radiographs in patients with $C D$.

Materials and methods: Panoramic radiographs obtained from 44 patients with CD were age- and sex-matched with 44 Class 1 (ANB: $2 \pm 2^{\circ}$ ) patients, and outcomes were analysed. Radiographs were digitised using Image I software, and condylar height, width, area, and perimeter were compared.

Results: Condylar area $\left(3.66 \pm 1.02 \mathrm{~cm}^{2}\right)$, perimeter $(9.29 \pm 1.38 \mathrm{~cm})$, and height $(2.69 \pm 0.46 \mathrm{~cm})$ values were significantly higher $(p<0.05)$ in the control group than those in the patient group (area: $2.52 \pm 0.63 \mathrm{~cm}^{2}$, perimeter: $8.47 \pm 1.42 \mathrm{~cm}$, height: $2.51 \pm 0.37 \mathrm{~cm}$ ), whereas width (coeliac: $2.83 \pm 0.63 \mathrm{~cm}$, control: $3.00 \pm 0.59 \mathrm{~cm})$ did not differ between the groups $(p>0.05)$.

Conclusions: These outcomes may be due to the low bone density of patients with $C D$. A controlled trial conducted using a larger sample is needed to support and extend these data. (Folia Morphol 2019; 78, 1: 191-194)

Key words: coeliac disease, mandibular condyle, panoramic, orthodontics

\section{INTRODUCTION}

Coeliac disease $(C D)$ is a chronic digestive disorder due to permanent intolerance to gluten [20]. $C D$ is described by total or sub-total atrophy of the proximal small intestinal mucosa villous, resulting in nutrient and vitamin deficiencies, particularly in infants and children [4]. It is mediated by an inflammatory $\mathrm{T}$ cell response to the storage proteins in some grains, particularly wheat (gliadin), rye (secalin), barley (hordein), and oats [5].

Many authors have reported oral problems in patients with CD, such as oral ulcers [3], delayed tooth eruption [30], salivary and oral ecosystem changes [21], and dental enamel defects. The low calcium concentration may cause hypoplasia of the enamel in patients with $C D[19,27]$.

Early diagnosis and treatment are crucial, as the mucous membranes will normalise with a gluten-free diet (GFD) [22]. Treatment with a GFD results in a rapid improvement in symptoms [11,22], but it also reduces bone mineral density (BMD) $[4,18]$, which is related to decreased calcium and vitamin $D$ intake and absorption as well as magnesium deficiency [12, 13]. There is no consensus in the literature regarding

Address for correspondence: Associate Prof. S. Kocahan, Department of Physiology, Faculty of Medicine, University of Adiyaman, Adiyaman, Turkey, e-mail: sayadkocahan@gmail.com, skocahan@adiyaman.edu.tr 
Table 1. Age and gender characteristics of control and coeliac disease (CD) groups

\begin{tabular}{lccc}
\hline & Control & CD & P \\
\hline Age [years] & $13.49 \pm 1.98$ & $13.51 \pm 1.98$ & 0.958 \\
Gender (female/male) & $25 / 19$ & $24 / 20$ & 0.832 \\
\hline
\end{tabular}

Data are shown as mean \pm standard deviation or number. There was no statistically significant difference between groups $(p>0.05)$.

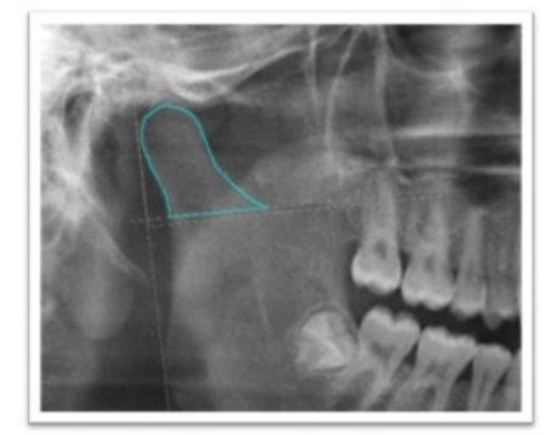

Figure 1. Condylar measurement system. Illustration of mandibular condylar height, width, area, and perimeter on digital panoramic radiographs.

bone mineralisation in children with $C D$. Exner et al. [10] suggested that forearm BMD does not change in children $>3$ years of age with CD. Mora et al. [24, 25] showed a significant reduction in forearm BMD and a remarkable reduction in lumbar spine BMD in children diagnosed with CD. These clues indicate a risk of malfunction in children's facial skeletal development having CD. However, no studies were noticed directly about the failures of growth and development of maxilla-mandibular complex in young individuals suffering $C D$.

The condyle is the key anatomic section of mandible that is responsible for sagittal and vertical growth of the whole mandibular bone [9]. The changes in these osseous structures may directly effect on facial skeletal profiles. Therefore, it would be favourable to investigate the changes in condylar anatomy for the initial step.

The aim of this study was to compare mandibular condylar height, width, area, and perimeter on digital panoramic radiographs from children with $C D$ versus healthy controls.

\section{MATERIALS AND METHODS}

In total, 88 individual were included in this study. The study group consisted of 44 ( 24 girls and 20 boys) randomly selected, untreated patients ranging in age from 12 to 16 years (mean \pm standard deviation [SD]:
$13.51 \pm 1.98$ years) with CD from Gaziantep University Faculty of Medicine Department of Paediatric Gastroenterology (Table 1). Serological tests, a small bowel biopsy during upper endoscopy, histological evidence of villous atrophy with hyperplasia of the crypts, and an increased number of intraepithelial lymphocytes were used to diagnose $C D$. This study was approved by the Clinical Research Ethical Committee of Gaziantep University (date: 18.12.2012, no. 449).

The control group consisted of 44 (25 girls and 19 boys) patients ranging in age from 12 to 16 (13.49 \pm 1.98 years) with skeletal Class 1 dental crowding who received basic orthodontic treatment at the Gaziantep University School of Dentistry Department of Orthodontics (Table 1). Each patient with $C D$ was age- and sex-matched with one of these 44 control patients (ANB: $2 \pm 2^{\circ}$ ). Panoramic radiographs were taken of all study participants. The radiographs were taken with a Planmeca Promax device (Planmeca Oy, Helsinki, Finland) and operated at 64 kV, 6 mA and $16 \mathrm{~s}$ by the same technician. Pre-treatment panoramic radiographs were used for the control group.

The area, perimeter, width, and height values of the mandibular condyle were calculated using image analysis software (Image J 1.33u; National Institutes of Health, Bethesda, MD, USA) using a 15.6" laptop computer (HP Pavillon G6, Palo Alto, California, USA) and a monitor (32 bit real colour, $1366 \times 768$ resolution, intel [R] HD Graphics 3000 adapter) by the same operator and were compared between the groups. The radiological landmarks used were based on the method of Momjian et al. [23] for condylar measurements on panoramic radiographs as shown in Figure 1.

\section{Statistical analysis}

The statistical analysis was performed using SPSS V.11.5 (SPPS Inc., Chicago, IL, USA). Sample size was estimated using a power calculation based on an increase of one unit in ANB in the coeliac group. It was estimated that at least 20 patients would be required to detect a significant difference between the control and coeliac groups at a power level of $80 \%$ and an alpha error of 5\%. A p-value $<0.05$ was considered significant. The Kolmogorov-Smirnov test was used to determine normality of the continuous variable distribution. The Student's t-test was used to compare the data of normally distributed variables. Frequencies, percentages, and means \pm SD are provided as descriptive statistics. 
Table 2. Condylar measurements in the coeliac disease (CD) and control groups

\begin{tabular}{llccc}
\hline Value & & Mean & SD & P \\
\hline Area $\left[\mathrm{cm}^{2}\right]$ & Control & 3.66 & 1.02 & $0.001^{*}$ \\
& CD & 2.52 & 0.63 & \\
Perimeter $[\mathrm{cm}]$ & Control & 9.29 & 1.38 & $0.008^{*}$ \\
& CD & 8.47 & 1.42 & \\
Height $[\mathrm{cm}]$ & Control & 2.69 & 0.46 & $0.044^{*}$ \\
& CD & 2.51 & 0.37 & \\
Width $[\mathrm{cm}]$ & Control & 3.00 & 0.59 & 0.194 \\
& CD & 2.83 & 0.63 & \\
\hline
\end{tabular}

${ }^{*}$ Statistically significant difference between groups $(p<0.05)$. SD — standard deviation

\section{RESULTS}

Age and gender characteristics of coeliac and control groups were given in Table 1. There were no significant differences regarding age $(p=0.958)$ and sex $(p=0.832)$ characteristics between groups. The results of the condylar measurements in the two groups are shown in Table 2 . The area $(p=0.001)$, perimeter $(p=0.008)$, and height measurements $(p=0.044)$ were significantly $(p<0.05)$ higher in the control group than CD group. No significant difference in width was detected between the groups $(p=0.194)$ as shown in Table 2 .

\section{DISCUSSION}

Low skeletal BMD is prevalent in patients with untreated $C D$ and it could result in growth retardation of maxillary and mandibular bones in growth period $[4,22,31]$. The overall bone indexes in children with this disease may commonly have risk of low bone density formation accompanying with skeletal porosity, malformation, deficiency in growth and maturation [28].

Othman and Ouda [26] showed that mandibular radiomorphometric measurements, such as the cortical index, mental index, and panoramic mandibular index, which are used to assess bone morphology and quality. Studies indicated that diseases progressing with bone loss such as osteoporosis may manifest lower mandibular morphometric measurements in panoramic radiographs $[2,8,14,17,32]$. Therefore, in this study, digital panoramic radiographs were used to detect differences in condylar morphology between children that suffered from CD and healthy controls.

According to our results, the patients with $C D$ were significantly associated with lower mandibu- lar condyle area, perimeter, and height values compared with the control group. These findings are in agreement with Horner et al. [14] that suggested a correlation between mandibular bone mass and overall skeletal bone mass. Our findings may result from some biochemical alterations, such as vitamin $D$ deficiency, secondary hyperparathyroidism, intestinal calcium malabsorption, and hypocalciuria which may influence condylar growth $[6,16,29]$. It could be mentioned that reduced condylar growth decreases the size of the mandible $[9,23]$. However, no differences in condylar width were found between the groups. The reason of this could be the attachments of medial pterygoid muscle that has a transversal direction of force vectors to the condyle.

Findings of the present study are in accordance with BMD studies in which bone absorptiometry was performed in children with $C D[15,24]$. Mora et al. $[24,25]$ showed a significant reduction in forearm $B M D$ and a remarkable reduction in lumbar spine BMD in children diagnosed with CD. Kalayci et al. [15] reported that BMD and bone mineral content values in coeliac patients were significantly lower than the healthy controls.

Although no specific studies were found on relationship between $C D$ and maxilla-mandibular structures in the literature, our findings are compatible with the studies showing mineralisation disturbances of teeth that may be caused by low calcium concentrations in $C D[1,7,27]$. Aine et al. [1] suggested that in $96 \%$ of 76 Finnish children have mineralisation disturbances and in $29 \%$ of them have poor enamel formations. Paez et al. [27] indicated that 30 children diagnosed with CD have statistically more systematic enamel defects compared with healthy controls in the same phase of dentition.

The first limitation of this study was that the measurements were taken from two-dimensional radiographs reflecting three-dimensional (3D) structures. Future studies using 3D radiographs are needed to achieve more accurate results. Another limitation was not evaluating the sagittal relationship. Sagittal positioning of the mandible according to the cranial base in patients with $\mathrm{CD}$ may help mandible morphology and size analyses.

\section{CONCLUSIONS}

In conclusion, patients with $C D$ exhibited lower condylar area, perimeter and height values, which should be taken into account in skeletal diagnosis of 
adolescents having CD. Further studies with larger sample sizes and with computer programme which calculate condylar measurements automatically on panoramic radiographs are needed to achieve more accurate results.

\section{REFERENCES}

1. Aine L, Mäki $M$, Collin $P$, et al. Dental enamel defects in celiac disease. J Oral Pathol Med. 1990; 19(6): 241-245, indexed in Pubmed: 2401959.

2. Bollen AM, Taguchi A, Hujoel PP, et al. Case-control study on self-reported osteoporotic fractures and mandibular cortical bone. Oral Surg Oral Med Oral Pathol Oral Radiol Endod. 2000; 90(4): 518-524, doi: 10.1067/moe.2000.107802, indexed in Pubmed: 11027391.

3. Campisi G, Di Liberto C, Carroccio A, et al. Coeliac disease: oral ulcer prevalence, assessment of risk and association with gluten-free diet in children. Dig Liver Dis. 2008; 40(2): 104-107, doi: 10.1016/j.dld.2007.10.009, indexed in Pubmed: 18063428.

4. Caraceni MP, Molteni N, Bardella MT, et al. Bone and mineral metabolism in adult celiac disease. Am J Gastroenterol. 1988; 83: 274-277.

5. Catassi C, Rätsch IM, Fabiani E, et al. Coeliac disease in the year 2000: exploring the iceberg. Lancet. 1994; 343(8891): 200-203, indexed in Pubmed: 7904667.

6. Ciacci C, Cirillo M, Mellone M, et al. Hypocalciuria in overt and subclinical celiac disease. Am J Gastroenterol. 1995; 90(9): 1480-1484, indexed in Pubmed: 7661174.

7. de Carvalho FK, de Queiroz AM, Bezerra da Silva RA, et al. Oral aspects in celiac disease children: clinical and dental enamel chemical evaluation. Oral Surg Oral Med Oral Pathol Oral Radiol. 2015; 119(6): 636-643, doi: 10.1016/j. oooo.2015.02.483, indexed in Pubmed: 25840513.

8. Devlin $\mathrm{H}$, Horner K. Mandibular radiomorphometric indices in the diagnosis of reduced skeletal bone mineral density. Osteoporos Int. 2002; 13(5): 373-378, doi: 10.1007/ s001980200042, indexed in Pubmed: 12086347.

9. Enlow DH, Moyers RE. Handbook of facial growth. WB Saunders, Philadelphia 1982.

10. Exner GU, Sacher M, Shmerling DH, et al. Growth retardation and bone mineral status in children with coeliac disease recognized after the age of 3 years. Helv Paediatr Acta. 1978; 33(6): 497-507, indexed in Pubmed: 216653.

11. Farrell R, Kelly C. Celiac sprue. N Engl J Med. 2002; 346(3): 180-188, doi: 10.1056/nejmra010852.

12. Fornari MC, Pedreira S, Niveloni $S$, et al. Pre- and post-treatment serum levels of cytokines IL-1 beta, IL-6, and IL-1 receptor antagonist in celiac disease. Are they related to the associated osteopenia? Am J Gastroenterol. 1998; 93(3): 413-418, doi: 10.1111/j.1572-0241.1998.00413.x, indexed in Pubmed: 9580142.

13. Gemme G, Vignolo M, Naselli A, et al. Linear growth and skeletal maturation in subjects with treated celiac disease. J Pediatr Gastroenterol Nutr. 1999; 29(3): 339-342, indexed in Pubmed: 10468002

14. Horner K, Devlin H, Alsop CW, et al. Mandibular bone mineral density as a predictor of skeletal osteoporosis. Br J Radiol. 1996; 69(827): 1019-1025, doi: 10.1259/0007-1285-69827-1019, indexed in Pubmed: 8958019.

15. Kalayci AG, Kansu A, Girgin N, et al. Bone mineral density and importance of a gluten-free diet in patients with celiac disease in childhood. Pediatrics. 2001; 108(5): E89, indexed in Pubmed: 11694673.

16. Keaveny AP, Freaney R, McKenna MJ, et al. Bone remodeling indices and secondary hyperparathyroidism in celiac disease.
Am J Gastroenterol. 1996; 91(6): 1226-1231, indexed in Pubmed: 8651176.

17. Klemetti E, Kolmakov S, Kröger H. Pantomography in assessment of the osteoporosis risk group. Scand J Dent Res. 1994; 102(1): 68-72, indexed in Pubmed: 8153584.

18. Kotze LMS, Skare T, Vinholi A, et al. Impact of a gluten-free diet on bone mineral density in celiac patients. Rev Esp Enferm Dig. 2016; 108(2): 84-88, doi: 10.17235/ reed.2015.3953/2015, indexed in Pubmed: 26838490.

19. Lähteenoja $H$, Toivanen $A$, Viander $M$, et al. Oral mucosal changes in coeliac patients on a gluten-free diet. Eur J Oral Sci. 1998; 106(5): 899-906, indexed in Pubmed: 9786318.

20. Mearin ML. Celiac disease among children and adolescents. Curr Probl Pediatr Adolesc Health Care. 2007; 37(3): 86-105, doi: 10.1016/j.cppeds.2007.01.001, indexed in Pubmed: 17320793.

21. Mina S, Riga C, Azcurra Al, et al. Oral ecosystem alterations in celiac children: a follow-up study. Arch Oral Biol. 2012; 57(2): 154-160, doi: 10.1016/j.archoralbio.2011.08.017, indexed in Pubmed: 21920498.

22. Molteni N, Caraceni MP, Bardella MT, et al. Bone mineral density in adult celiac patients and the effect of gluten-free diet from childhood. Am J Gastroenterol. 1990; 85(1): 51-53, indexed in Pubmed: 2296964.

23. Momjian A, Courvoisier D, Kiliaridis S, et al. Reliability of computational measurement of the condyles on digital panoramic radiographs. Dentomaxillofac Radiol. 2011; 40(7): 444-450, doi: 10.1259/dmfr/83507370, indexed in Pubmed: 21960403

24. Mora S, Barera G, Ricotti A, et al. Reversal of low bone density with a gluten-free diet in children and adolescents with celiac disease. Am J Clin Nutr. 1998; 67(3): 477-481, doi: 10.1093/ajcn/67.3.477, indexed in Pubmed: 9497193.

25. Mora S, Weber G, Barera G, et al. Effect of gluten-free diet on bone mineral content in growing patients with celiac disease. Am J Clin Nutr. 1993; 57(2): 224-228, doi: 10.1093/ ajcn/57.2.224, indexed in Pubmed: 8424392.

26. Othman H, Ouda S. Mandibular radiomorphometric measurements as indicators of possible osteoporosis in celiac patients. J King Abdulaziz University-Medical Sciences. 2010; 17(2): 21-35, doi: 10.4197/med.17-2.3.

27. Páez E, Lafuente $P$, García $P$, et al. Prevalence of dental enamel defects in celiac patients with deciduous dentition: a pilot study. Oral Surg Oral Med Oral Pathol Oral Radiol Endod. 2008; 106(1): 74-78, doi: 10.1016/j.tripleo.2008.01.022.

28. Pritchard L, Lewis SJ, Griffin J, et al. PTU-155 Investigation of the relationship between age, gender, body mass index (BMI) and bone mineral density (BMD) as assessed by dual-energy $x$-ray absorptiometry (DXA) of the spine and left femur in newly diagnosed patients with coeliac disease (CD). BMJ Publish Group. 2015; 64: A131-A131, doi: 10.1136/ gutjnl-2015-309861.270.

29. Smecuol E, Mauriño E, Vazquez H, et al. Gynaecological and obstetric disorders in coeliac disease: frequent clinical onset during pregnancy or the puerperium. Eur J Gastroenterol Hepatol. 1996; 8(1): 63-89, indexed in Pubmed: 8900911.

30. Suri L, Gagari E, Vastardis H. Delayed tooth eruption: Pathogenesis, diagnosis, and treatment. A literature review. Am J Orthod Dentofacial Orthop. 2004; 126(4): 432-445, doi: 10.1016/j.ajodo.2003.10.031.

31. Valdimarsson $T$, Toss $G$, Ross I, et al. Bone mineral density in coeliac disease. Scand J Gastroenterol. 1994; 29(5): 457-461, indexed in Pubmed: 8036462.

32. Vlasiadis KZ, Skouteris CA, Velegrakis GA, et al. Mandibular radiomorphometric measurements as indicators of possible osteoporosis in postmenopausal women. Maturitas. 2007; 58(3): 226-235, doi: 10.1016/j.maturitas.2007.08.014, indexed in Pubmed: 17923346. 